\title{
The Blind Leading the Blind: Who Gets Polling Information and Does it Improve Decisions?
}

\author{
Cheryl Boudreau \\ Assistant Professor \\ University of California, Davis \\ Department of Political Science \\ One Shields Avenue \\ Davis, CA 95616 \\ Phone: (530) 752-8128 \\ clboudreau@ucdavis.edu \\ Mathew D. McCubbins \\ Distinguished Professor \\ University of California, San Diego \\ Department of Political Science \\ 9500 Gilman Drive, Mail Code 0521 \\ La Jolla, CA 92093-0521 \\ Phone: (858) 534-3733 \\ mmccubbins@ucsd.edu
}

*We thank the National Science Foundation (Grant \#SES-0616904) and the Kavli Institute for Brain and Mind for providing financial support for these experiments. We are also grateful to Gary Cox, Bob Huckfeldt, Cindy Kam, Skip Lupia, Scott MacKenzie, Sam Popkin, and members of the micro-politics group at the University of California, Davis for helpful comments on this project. 


\begin{abstract}
We analyze whether and when polls help citizens to improve their decisions. Specifically, we use experiments to investigate 1) whether and when citizens are willing to obtain polls and 2) whether and when polls help citizens to make better choices than they would have made on their own. We find that citizens are more likely to obtain polls when the decisions they must make are difficult and when they are unsophisticated. Ironically, when the decisions are difficult, the pollees are also uninformed and, therefore, do not provide useful information. We also find that when polls indicate the welfare-improving choice, citizens are able to improve their decisions. However, when polls indicate a choice that will make citizens worse off, citizens make worse decisions than they would have made on their own. These results hold regardless of whether the majority in favor of one option over the other is small or large.
\end{abstract}


How do polls affect citizens' decisions? Ever since polling proliferated in the early $20^{\text {th }}$ century, citizens in our country have been bombarded with facts and figures regarding what the “typical" American thinks, feels, and intends to do (Igo 2007; Herbst 1993). For example, when covering campaigns, the media frequently report poll results indicating the percentage of citizens who intend to vote for one candidate over the other, the percentage of citizens who think that a given candidate is qualified, and so on. When discussing policy proposals, the media often present polls showing the percentage of citizens who support or oppose the policy in question. Similarly, the media report the results of polls that reflect citizens' beliefs about factual matters, such as whether Saddam Hussein had weapons of mass destruction or whether Barack Obama is a Muslim. Related polls are conducted in economic contexts, where businesses report poll results showing that a majority of consumers prefer their brand to their competitors' brands.

Given the countless polls that are conducted and publicized in political and economic contexts, it is not surprising that scholars question whether and how polls influence citizens. Although some scholars suggest that polls provide uninformed citizens with cues that may aid them with their decisions (Popkin 1991; Bartels 1988; Mutz 1992; Key 1966), others argue that polls may have harmful effects because political elites and the media can manipulate them (Jacobs and Shapiro 1995-1996; Lippman 1925; Polsby and Wildavsky 1980; West 1991). Such concerns about polls have been heightened in recent years because of the media's tendency to make poll results appear overly precise ${ }^{1}$ and scientific when in fact many polls are plagued by inaccuracies and biases (Herbst 1993; Igo 2007; Lau 1994; Franklin 2003; Jackman 2005). These concerns, viewed in light of research showing that polls influence citizens' beliefs and behaviors (e.g., Hardy and Jamieson 2005; Mutz 1997; Ansolabehere and Iyengar 1994), make it 
important to analyze 1) the conditions under which citizens seek out and use polls and 2) whether and when polls help citizens to make better decisions than they would have made on their own.

We analyze both of these questions by conducting laboratory experiments. Specifically, we randomly assign subjects to either a control group (where subjects make their decisions on their own) or to one of several different treatment groups (where subjects have the option to receive poll results before making their decisions). Our results show that subjects are more likely to obtain polls when the decisions they must make are difficult and when they are unsophisticated. This finding is disturbing given that the difficult decisions are the ones where 1) the pollees typically lack the knowledge to recommend welfare-improving choices and 2) subjects typically lack the sophistication to judge the accuracy of the pollees' recommendations.

Our results also show the effects that polls have on the quality of subjects' decisions. Specifically, our results demonstrate that when poll results indicate the welfare-improving choice, subjects who choose to receive them improve their decisions. However, when poll results indicate an option that will make subjects worse off, subjects are swayed by these polls and make worse decisions than they would have made on their own. Surprisingly, subjects are swayed by these polls even when the size of the majority picking one option over the other is not very large. Taken together, our results demonstrate that when it comes to polls, "the blind lead the blind." That is, subjects are more likely to obtain polls when the pollees are least likely to help them, and they consistently follow the recommendations of small, uninformed majorities.

\section{Do Polls Help or Harm?}

In response to scholars who lament citizens' lack of factual knowledge about politics (Berelson et al. 1954; Campbell et al. 1960; Converse 1964), many scholars argue that cues can 
substitute for knowledge about politics and help citizens make informed choices (Popkin 1991; Lupia and McCubbins 1998; Lupia 1994; Druckman 2001; Sniderman, Brody, and Tetlock 1991; Kam 2005). Although there are many cues that citizens can rely upon (party labels, endorsements, candidates' appearances, etc.), scholars emphasize that polls are particularly salient cues for citizens and that they influence citizens' decisions and perceptions (Popkin 1991; Kam and Sommer 2006; Bartels 1988; Mutz 1992; Irwin and Van Holsteyn 2002; Ceci and Kain 1982; see Geer 1996 for a discussion of how polls affect politicians). Indeed, given the dramatic increase in the number of polls reported in the media (Herbst 1993; Lavrakas and Traugott 2000; Igo 2007), it is not surprising that scholars emphasize the cue-taking aspects of public opinion poll reporting. Although these scholars suggest that polls can provide citizens with cues, many do not assess the conditions under which polls improve citizens' decisions.

In contrast to those who suggest that polls provide citizens with helpful cues, several scholars argue that polls may have harmful effects. Specifically, scholars in this camp suggest that political elites and the media can manipulate polls, which may enable them to sway citizens' preferences and voting decisions (Jacobs and Shapiro 1995-1996; Lippman 1925; Polsby and Wildavsky 1980; West 1991; Herbst 1993). For example, Jacobs and Shapiro (1995-1996) demonstrate that President Nixon tried to influence pollsters in order to misrepresent information about public opinion and enhance his own political power. Similarly, West (1991) emphasizes that if polls influence citizens' choices, then this gives tremendous power to elites and the media who control the dissemination of poll results. Further, Herbst (1993) and Igo (2007) suggest that modern polls often appear more precise and authoritative than they actually are and that polls often supplant other types of information about public opinion (such as interviews with activists). Based upon related fears about the effects of polls, several countries have restricted the 
publication of opinion polls during campaigns (McAllister and Studlar 1991). Taken together, this research recognizes that polls may have detrimental effects and underscores the importance of identifying the conditions under which polls do (and do not) have such effects.

It is this body of research on the effects of polls that we build on in this study. Specifically, we use experiments to investigate the conditions under which citizens are willing to obtain polls. We also assess the conditions under which polls help citizens to make better decisions than they would have made on their own. Although there are many experimental and survey-based studies of polls, our experiments are unique in that they allow subjects to choose whether and when they would like to receive polls. This aspect of our experiments is advantageous because it allows us to observe directly 1) whether and when citizens are willing to bear the costs of obtaining polls (which often take the form of foregone opportunities to do something else) and 2) which types of citizens (i.e. unsophisticated versus sophisticated) are more likely to seek out and use polls. Further, in contrast to many survey-based studies of polls (where scholars often do not know whether individuals receive particular poll results and must deal with confounding events that occur during campaigns; see Hardy and Jamieson 2005), our experiments enable us to isolate the effects that polls alone have on citizens' decisions and determine whether polls, by themselves, help citizens to make better decisions than they would have made on their own.

\section{Research Design}

In order to analyze the conditions under which polls help citizens to improve their decisions, we randomly assign subjects to either a control group or to one of several different treatment groups. We then ask subjects to answer a series of binary choice math problems (that 
is, subjects may choose whether answer "a" or answer "b" is correct). The math problems are drawn from an SAT math test and consist of many different types of problems and several levels of difficulty. We tell subjects in both the treatment and control groups that they have 60 seconds to answer each math problem ${ }^{2}$ and that they will earn 50 cents for each problem that they answer correctly, lose 50 cents for each problem that they answer incorrectly, and neither earn nor lose 50 cents if they leave a problem blank. We ask subjects to make choices about math problems (instead of asking them to vote for fictional candidates or policies), in part, because this task provides us with a straightforward way of identifying correct decisions and assessing whether and when polls induce an improvement in decision making. Stated differently, although it is often difficult to identify when citizens choose the "correct" candidate or policy, ${ }^{3}$ it is easy to tell when they choose the correct answer to a math problem.

The difference between the treatment and control groups has to do with the conditions under which subjects answer the math problems. In the control group, subjects answer the math problems on their own, which provides a baseline for how well subjects make these decisions when they do not have access to polls. In the treatment groups, subjects also answer these math problems. However, before subjects in the treatment groups make their decisions, they can choose to receive the results of polls that we conducted prior to the experiment.

Specifically, before running our experiments, we polled 66 college undergraduates about what they thought the correct answers to the different math problems were. We told these undergraduates that they could either answer each problem or leave it blank. This aspect of our design makes our polls analogous to real world polls in which "don't know" is an option. ${ }^{4}$ Then, if the undergraduates that we polled chose to answer a given problem, they could choose either answer "a" or answer "b." These undergraduates had 60 seconds to make a decision about each 
math problem, ${ }^{5}$ and they earned 50 cents each time they chose the correct answer, lost 50 cents each time they chose the incorrect answer, and neither earned nor lost 50 cents each time they left a problem blank. In this way, the polls that we conducted provide information about the number of undergraduates who chose to answer each math problem, as well as information about the number of undergraduates who thought that "a" was the correct choice and the number of undergraduates who thought that "b" was the correct choice. ${ }^{6}$

So, for each math problem, subjects in each treatment group are first given 60 seconds to determine what they think is the correct answer. This gives subjects an opportunity to solve the problem and to decide whether they want to receive the results of the poll that we conducted for that problem. If they choose to receive the poll results, then we provide them with that information; otherwise, we do not provide them with the poll results. ${ }^{7}$ Once we give the poll results to the subjects who choose to receive them, all subjects in the treatment groups have an additional 60 seconds to choose an answer to the problem. ${ }^{8}$ The answer that subjects mark at the end determines whether they earn money, lose money, or get nothing for each problem.

Although all subjects assigned to a treatment group have the option to receive the poll results, we manipulate whether subjects may receive the poll results for free or whether they must pay a small cost. We also manipulate whether the poll results are credible or not. This creates four different treatment groups in a $2 \times 2$ factorial research design: In one treatment group, subjects may receive poll results that they know to be credible for free. In the second treatment group, subjects may receive poll results that they do not know to be credible for free. In the third treatment group, subjects must pay a small cost if they would like to receive poll results that they know to be credible. In the fourth treatment group, subjects must pay a small cost if they would like to receive poll results that they do not know to be credible. We use a 
between-group research design in which separate groups of subjects are assigned to each of these treatment groups and to the control group. ${ }^{9}$ Each treatment group is described below.

\section{Treatment 1: Free Access to Credible Polls}

In this treatment group, subjects can receive the polls for free. That is, all they need to do to receive the polls is put a checkmark beside the line that asks whether they would like to receive information about what 66 other undergraduates recommend as the correct answer. Once subjects mark that they would like to receive this information, the experimenter provides it to them. This aspect of this treatment group is analogous to when citizens in the real world receive polls as a by-product of other activities and, therefore, do not pay any opportunity costs. For example, citizens surfing the Internet may see poll results in the margins of the webpage that they are reading or during the commercial break of the TV show that they are watching.

Further, subjects in this treatment group know that the poll results are credible. That is, subjects are told that the 66 undergraduates that we polled earned 50 cents every time they recommended the correct answer, lost 50 cents every time they recommended the incorrect answer, and earned nothing if they chose not to answer the problem. Thus, subjects know that the pollees had an incentive to answer the questions truthfully and have little reason to fear that the pollees' responses were not truthful. This aspect of this treatment group is analogous to the many real world contexts in which citizens have little or no reason to fear that the pollees' responses were not truthful. For example, real world polls showing that a majority of pollees support clean energy policies or that a majority of pollees oppose raising property taxes are polls that typically do not cause citizens to fear that the pollees' responses are untruthful. Although citizens may not base their decisions upon these polls for other reasons (namely, they may fear 
that the pollees are not knowledgeable about clean energy or property tax policies), there is little reason for them to question whether the pollees had an incentive to be truthful. And, just as citizens in the real world may fear that pollees lack knowledge about particular issues, so too may subjects in our experiments fear that the pollees lack knowledge about the correct answers to particular math problems. Thus, with this treatment group, we are able to assess the effects that polls have on citizens when they can receive them without paying a cost and when the pollees are credible, but not necessarily knowledgeable. ${ }^{10}$

\section{Treatment 2: Free Access to Non-Credible Polls}

In this treatment group, subjects can also receive the polls for free. However, because citizens in the real world do not always know whether pollees are credible, we do not tell subjects in this treatment group anything about the pollees' incentives. Specifically, we tell these subjects that, prior to the experiment, we asked 66 undergraduates about what they thought the correct answers to the math problems were, and we do not tell these subjects anything about how

these undergraduates earned money. ${ }^{11}$ Thus, although the undergraduates that we polled actually had an incentive to recommend correct answers (as described above), subjects did not know this. This aspect of this treatment group is analogous to the many real world contexts in which citizens may question whether pollees truthfully responded to the questions they were asked. For example, before the 2008 presidential election, many citizens and pundits questioned whether pollees truthfully revealed that they were going to vote for Barack Obama on Election Day or whether the poll results were driven by the Bradley Effect. Similarly, pollsters and others often question whether pollees truthfully report that they turned out to vote in particular elections. In contexts such as these, citizens who receive poll results may question whether the pollees' 
responses are truthful. Similarly, subjects in this treatment group may question whether the pollees' responses to the math problems were truthful. Thus, with this treatment group, we are able to assess the effects that polls have on citizens when they can receive them without paying a cost, but when they may reasonably question whether the pollees had an incentive to respond truthfully. ${ }^{12}$

\section{Treatment 3: Costly Access to Credible Polls}

In this treatment group, subjects must pay a small cost to receive the polls. Specifically, subjects must pay 10 cents each time they wish to receive information about what 66 other undergraduates recommend as the correct answer. ${ }^{13}$ This 10 -cent cost is designed to be analogous to the opportunity costs that citizens in the real world may face when they seek out poll results. ${ }^{14}$ As in the "Free Access to Credible Polls" treatment group, subjects know that the pollees had an incentive to recommend correct choices. That is, subjects are told that the 66 undergraduates that we polled earned 50 cents every time they recommended the correct answer, lost 50 cents every time they recommended the incorrect answer, and earned nothing if they chose not to answer the problem. As before, what subjects do not know is whether the pollees were capable of solving the math problems correctly. Thus, with this treatment group, we are able to assess the effects that polls have on citizens when they must pay a small cost to receive polls that they know to be credible, but that are not necessarily knowledgeable.

\section{Treatment 4: Costly Access to Non-Credible Polls}

In this treatment group, subjects must also pay 10 cents each time they wish to receive the poll results. However, as in the "Free Access to Non-Credible Polls" treatment group, we do 
not tell subjects in this treatment group anything about the pollees' incentives. That is, we tell these subjects that, prior to the experiment, we asked 66 undergraduates about what they thought the correct answers to the math problems were, and we do not tell these subjects anything about how these undergraduates earned money. Thus, with this treatment group, we are able to assess the effects that polls have on citizens when they must pay a small cost to receive the polls and when they may reasonably question whether the pollees had an incentive to respond truthfully.

\section{Natural Variations: Problem Difficulty and Subject Sophistication}

Because the math problems that we use vary in how difficult they are, subjects in our treatment groups receive dramatically different poll results for each math problem. That is, the size and direction of the majority recommending one option over the other naturally varies for each problem, depending upon the difficulty of the problem. Specifically, on the easy math problems, a large majority of the undergraduates that we polled recommended the correct answer. For example, on one of the easiest math problems, 59 pollees recommended the correct answer, 3 pollees recommended the incorrect answer, and 4 pollees chose not to answer the problem. However, on one of the most difficult math problems, a very large majority of undergraduates recommended the incorrect answer. For still other problems, there was not a large majority in favor of either option; that is, these poll results are closer to a 50-50 split.

These different distributions of opinion for each math problem enable us to assess the effects that the size and direction of the majority have on subjects' decisions. Indeed, this natural variation in the math problems allows us to analyze not only whether subjects in our treatment groups base their choices upon what the majority of the pollees recommends, but also how large this majority has to be before subjects are willing to follow it. ${ }^{15}$ And, because the poll results for 
each math problem reflect how difficult each problem is (i.e., problems with more pollees recommending the correct answer are easier problems than those with fewer pollees recommending the correct answer), we are also able to assess whether subjects are more or less likely to receive poll results when the decisions they must make are difficult versus easy.

Another natural variation that we take advantage of is subjects' varying levels of sophistication. Because we recruited a broad range of subjects and randomly assigned them to a treatment or control group, we have a mix of sophisticated and unsophisticated subjects in each treatment group and in the control group. Further, because we collect subjects' SAT math scores prior to the experiment, ${ }^{16}$ we have a valid and reliable measure of how sophisticated subjects are at answering math problems. In this way, we are able to examine whether unsophisticated subjects are more or less likely than sophisticated subjects to obtain polls.

This measure of subjects' sophistication is another important advantage associated with asking subjects to make decisions about math problems. Indeed, although an agreed upon measure of political sophistication does not exist (see, e.g., Luskin 1987), there does exist an agreed upon, widely used, and straightforward measure of mathematical sophistication. Further, subjects' SAT math scores provide us with a measure of sophistication that is directly related to the task that subjects perform in our experiment (i.e., solving math problems). This also represents an improvement upon existing research because scholars often use a measure of sophistication that is not directly related to the task they seek to study. Specifically, scholars frequently measure political sophistication as the ability to answer factual questions about politics (see, e.g., Delli Carpini and Keeter 1996). Measures of this nature, however, may not have a strong relationship to the tasks that subjects perform in an experiment (for example, voting in a mock election, expressing an attitude about a particular policy, etc.) or to the tasks 
that citizens perform in the real world (i.e., voting for particular candidates or policies). By using SAT math scores as our measure of sophistication, we are able to use a measure of sophistication that directly relates to the task that subjects perform in our experiment.

\section{External Validity: Connecting Math Problems to Politics}

Even though math problems do not look like political decisions on the surface, they capture many key characteristics of political decisions. Thus, they can tell us a great deal about how citizens in the real world make political choices. At the most basic level, citizens making political decisions often choose between two options (e.g., voting "yes" or "no" on an initiative, voting for the incumbent or the challenger) that will have different effects on their welfare in the future (Fowler and Kam 2006). Similarly, our subjects must choose between two options ("a" or "b") that also have different effects on their future welfare. Indeed, because subjects in our experiments 1) earn money for correct choices and lose money for incorrect choices, 2) are not paid for their decisions until the end of the experiment, and 3) are not given feedback about their decisions until the end of the experiment, the choices they make affect their future welfare.

Although most political decisions affect citizens' welfare (and, thus, there is something at stake when citizens make political decisions), the stakes are often perceived to be small. Indeed, although some citizens perceive the stakes to be large when making decisions about hot-button political issues (such as abortion), research suggests that typical political issues are low stakes games for most Americans (Hibbing and Theiss-Morse 2002). Thus, in our experiments, we ensure that there is something at stake for subjects (money), but that, as in many real world political contexts, the stakes are not large (subjects earn or lose 50 cents for each decision). 
Another similarity between making decisions about math problems and making decisions about politics pertains to the preexisting knowledge that citizens in the real world and subjects in our experiments possess. Specifically, in real world politics, citizens are not blank slates when they go to the ballot box; that is, they may have preexisting knowledge about the candidates and policies that they are choosing from. Similarly, subjects in our experiments are not blank slates when they make their decisions about whether "a" or " $b$ " is the best choice for them because they may have preexisting knowledge about how to answer particular math problems.

That said, citizens in the real world might be uncertain about their decisions; that is, they may not know which candidate or policy will make them better off. This is especially true when party labels are not attached to the options from which voters must choose, as is the case in nonpartisan elections, ballots containing initiatives, etc. Similarly, subjects in our experiments may be uncertain about whether choosing "a" or "b" will make them better off. As in the real world, the uncertainty that subjects experience depends, in part, upon their levels of sophistication. Indeed, just as unsophisticated citizens in the real world may be more uncertain about which choice will make them better off, so too may unsophisticated subjects in our experiments be more uncertain about whether "a" or " $b$ " is the best choice. And, just as citizens in the real world vary in their levels of sophistication, so too do our subjects, as their SAT math scores range from 400 (the $14^{\text {th }}$ percentile) to 800 (a perfect score).

Further, citizens in the real world often receive poll results, and they must then make decisions about which option will make them better off. For example, citizens may receive polls showing that a majority of citizens support a particular candidate, and they must then decide whether they should choose that candidate when they go to the ballot box. Similarly, subjects in our experiments receive polls showing that a majority of undergraduates recommend a particular 
answer, and they must then make decisions about whether they should choose "a" or "b." Admittedly, the questions on many political polls are subjective (i.e., should abortion be legal, do you support or oppose the war in Iraq), and we recognize that there are differences between this type of poll and the polls used in our experiments. That said, there are many political polls that ask objectively correct or incorrect questions. For example, a 2003 Washington Post poll asked citizens the following questions: "How likely is it that Saddam Hussein was personally involved in the September 11 terrorist attacks?" and "How likely is it that Saddam Hussein had already developed weapons of mass destruction?" In contrast to more subjective opinion polls, this type of poll contains questions about information that is objectively correct or incorrect. The polls in our experiments are designed to be analogous to these more objective polls; thus, they tell us a great deal about the effects that this type of poll has on citizens' decisions.

Finally, some types of political decisions either implicitly or explicitly involve solving math problems. For example, ballot initiatives regarding school funding policies, property tax policies, and other economic policies often involve math problems that citizens must solve to determine if particular policies benefit them and what the net impact of these policies is. Similarly, evaluating politicians' statements about the consequences of social security privatization involves calculations about whether and when private accounts will yield a higher rate of return than the current system. In the real world (as in our experiments), these decisions can be difficult not only because the problem is complex, but also because poll results may not indicate the "correct" or welfare-improving solution. Given the many similarities between real world political decisions and decisions about math problems, there is a close mapping between the psychological processes of subjects in our experiments and the psychological processes of voters in real world contexts (Aronson, Wilson, and Brewer 1998). 


\section{Hypotheses}

The experiments described above yield a number of predictions about the conditions under which subjects should be more (or less) likely to choose to receive polls. Specifically, we expect subjects to be more likely to receive polls when they can receive them for free, as opposed to when they must pay a cost, all else constant. Thus, subjects should be more likely to receive polls when they are free and credible than when they are costly and credible. Subjects should also be more likely to receive polls when they are free and non-credible than when they are costly and non-credible. We also predict that subjects will be more likely to receive polls when they know the polls are credible, as opposed to non-credible, all else constant. Thus, subjects should be more likely to receive polls when they are free and credible than when they are free and non-credible. Subjects should also be more likely to receive polls when they are costly and credible than when they are costly and non-credible. Further, we expect subjects to be more likely to receive polls when they are unsophisticated (as opposed to sophisticated) and when the problems are difficult (as opposed to easy).

The logic behind each of these predictions is straightforward. When receiving polls is costly, the cost of the polls may exceed their value for some subjects. This is not the case when subjects can receive polls for free. Further, when subjects know that the polls are credible, the perceived quality of that information is higher than when the polls are not known to be credible. Thus, all else constant, subjects should be more likely to receive credible polls than non-credible polls. Additionally, unsophisticated subjects (who typically lack the ability to make correct decisions on their own) are more likely to need the information that polls provide, and subjects, in the aggregate, are more likely to need polling information when the decisions are more difficult. Stated differently, subjects who can make correct decisions on their own (either 
because they are sophisticated or because the problem is easy) should be less likely to receive polls, all else constant.

As for how polls should affect the quality of subjects' decisions once they choose to receive them, this depends upon subjects' beliefs about the sophistication levels of the 66 undergraduates that we polled, relative to their self-evaluations of their own levels of sophistication. For example, if a subject believes that the 66 undergraduates that we polled are more sophisticated than he or she is, then that subject should base his or her decision on what the majority of pollees recommends, especially if the poll is known to be credible. If a subject believes that the 66 pollees are less sophisticated than he or she is, then that subject should ignore the poll results if the majority recommends an answer that differs from his or her own perceptions of the correct answer. Because subjects are not told whether the undergraduates that we polled are knowledgeable about solving math problems, we must simply observe ex post the quality of their decisions in each treatment group, with correct versus incorrect poll results, and with different margins between the number of pollees recommending one answer over the other.

\section{Data and Methodology}

To test our hypotheses, we conducted laboratory experiments at a large public university. When recruiting subjects, we posted flyers on campus and sent out campus-wide emails to advertise the experiments. A total of 236 adults who were enrolled in undergraduate classes participated. Of these 236 subjects, 42 were randomly assigned to the "Free Access to Credible Polls" treatment group, 49 were assigned to the "Free Access to Non-Credible Polls" group, 37 were assigned to the "Costly Access to Credible Polls" group, 42 were assigned to the "Costly Access to Non-Credible Polls" group, and 66 were assigned to the control group. 
When analyzing the data gleaned from these experiments, we first assess whether and when subjects choose to receive polls. Specifically, we estimate the following model: ReceivePoll $=\alpha+\beta$ Treatment $1+\beta$ Treatment $2+\beta$ Treatment $3+\beta$ Sophistication +

$$
\beta \text { Difficulty }+\beta \text { SchoolYear }+\beta \text { Female }+\epsilon
$$

In this model, ReceivePoll is a dummy variable that reflects whether a subject chooses to receive a poll on each problem (coded 1 if a subject chooses to receive a poll and 0 otherwise). The Treatment 1 variable reflects participation in Treatment group 1 (i.e., where polls are available, free, and credible) and is coded 1 if a subject is in Treatment group 1 and 0 otherwise. The Treatment 2 variable reflects participation in Treatment group 2 (i.e., where polls are available, free, and not credible) and is coded 1 if a subject is in Treatment group 2 and 0 otherwise. The Treatment3 variable reflects participation in Treatment group 3 (i.e., where polls are available, costly, and credible) and is coded 1 if a subject is in Treatment group 3 and 0 otherwise. The Sophistication variable reflects subjects' SAT math scores, and the Difficulty variable indicates the level of difficulty of each math problem (higher values of this variable reflect a harder problem). The variables SchoolYear and Female indicate subjects' year in school and gender, respectively. ${ }^{17}$ Treatment group 4 (where polls are available, costly, and not credible) is the omitted category in this regression.

We estimate the above model using a logistic regression and a random effects logistic regression. We include a random effects model to capture unobserved individual (i.e., subject) heterogeneity and to demonstrate that our results do not change when such unobserved individual heterogeneity is modeled. Substantively, this analysis enables us to assess whether subjects are more likely to receive polls when the decisions they must make are difficult and 
when they are more (or less) sophisticated. It also allows us to analyze whether subjects are more (or less) likely to receive polls in particular treatment groups.

Second, we assess whether and when polls help subjects to improve their decisions and, by extension, their welfare. Because subjects earn money for each correct decision, lose money for each incorrect decision, and neither earn nor lose money for each blank answer, we use the amount of money that each subject earns on each problem as a measure of the quality of subjects' decisions. ${ }^{18}$ Specifically, we estimate the following model: MoneyEarned $=\alpha+\beta$ Treatment $1+\beta$ Treatment $2+\beta$ Treatment $3+\beta$ Treatment $4+$

$$
\begin{aligned}
& \beta \text { Sophistication }+\beta \text { Difficulty }+\beta \text { ReceivePoll } * \text { Treatment } 1+ \\
& \beta \text { ReceivePoll*Treatment } 2+\beta \text { ReceivePoll*Treatment } 3+ \\
& \beta \text { ReceivePoll } * \text { Treatment } 4+\beta \text { ReceivePoll*Sophistication }+ \\
& \beta \text { ReceivePoll } * \text { Difficulty }+\beta \text { ReceivePoll } * \text { MajorityMargin }+ \\
& \beta \text { ReceivePoll*MajorityIncorrect }+\beta \text { SchoolYear }+\beta \text { Female }+\epsilon
\end{aligned}
$$

In this model, MoneyEarned is a variable that reflects the amount of money that a subject earns on each problem (coded $\$ 0.50$ if a subject answers correctly, $\$-0.50$ if a subject answers incorrectly, and $\$ 0$ if a subject leaves the problem blank). ${ }^{19}$ Thus, our unit of analysis is subjectproblem observations. ${ }^{20}$ The Treatment1, Treatment2, Treatment3, Treatment4, Sophistication, and Difficulty variables are coded as described above. We also interact each of these variables with a ReceivePoll dummy variable (coded 1 if a subject chooses to receive a poll and 0 otherwise). We also include an interaction between ReceivePoll and a MajorityIncorrect dummy variable (coded 1 if a majority of pollees recommend the incorrect answer and 0 otherwise), as well as an interaction between ReceivePoll and a MajorityMargin variable (which reflects the absolute value of the difference between the number of pollees choosing "a" versus "b"). As in 
the previous model, we control for subjects' year in school and gender. The omitted category in this model is the control group.

The main variables of interest in this analysis are the interaction terms because they capture the effects of receiving polls under different conditions. Specifically, significant positive coefficients for the interactions between ReceivePoll and each treatment dummy variable would indicate that receiving polls improves subjects' decisions within a given treatment group. A significant negative coefficient for the interaction between ReceivePoll and MajorityIncorrect would indicate that receiving incorrect poll results induces subjects to make worse decisions. A significant positive coefficient for the interaction between ReceivePoll and MajorityMargin would indicate that the larger the majority picking one option (in this case, the correct option) over the other, the better decisions subjects make. We estimate this model using both ordinary least squares (OLS) and random effects generalized least squares (GLS) regressions ${ }^{21}$ to ensure that our results are robust to unobserved individual heterogeneity.

\section{Results: The Blind Lead the Blind}

Our results show that subjects are more likely to receive polls when the polls are least likely to help them. Specifically, Table 1 demonstrates that subjects are more likely to receive polls when the decisions that they must make are more difficult. Indeed, as shown in Table 2, moving from the easiest problem in the experiment (which $89 \%$ of the pollees answered correctly) to the hardest problem (which only $6 \%$ of the pollees answered correctly) increases the chance that subjects choose to receive a poll by approximately $16 \%{ }^{22}$ Although this result is not surprising (indeed, we did not expect subjects to choose to receive polls when the decisions that they must make are easy), it is quite ironic because the hardest problems in the experiment are 
the ones where the pollees are less likely to recommend the correct answer. Thus, subjects are more likely to choose to receive polls in situations where their fellow undergraduates are also uninformed about the correct choice.

[Tables 1 and 2 about here]

As expected, we also find that unsophisticated subjects are more likely to choose to receive polls than are sophisticated subjects. Specifically, Table 2 shows that moving from the most sophisticated subject (who scored an 800 on his or her SAT math test) to the least sophisticated subject (who scored a 400 on his or her SAT math test) increases the chance that subjects will receive a poll by $29 \%$. Although it is also not surprising that the least sophisticated are more likely to choose to receive polls, these results demonstrate that the blind lead the blind in our experiments. Indeed, these results indicate that subjects who lack the sophistication to judge whether the polls are correct are the ones who are more likely to receive them, even when their fellow undergraduates are unlikely to know any more than they do.

Contrary to our expectations, the results in Tables 1 and 2 also demonstrate that subjects are equally likely to receive polls when the poll results are credible versus non-credible. That is, although subjects are significantly more likely to choose to receive polls when it is free to receive them (compared to when they must pay a cost), there is not a significant difference in the probability that subjects choose to receive polls when 1) the poll results are free and credible versus free and non-credible and 2) the poll results are costly and credible versus costly and noncredible. Thus, regardless of whether polls are free or costly, subjects are just as likely to choose to receive polls when they know that the pollees had a financial incentive to recommend correct choices versus when they do not know anything about the pollees' incentives. Thus, not only do 
the "blind" pollees lead the "blind" subjects, but subjects also do not appear to distinguish between credible and non-credible polls. ${ }^{23}$

\section{Consequences of Receiving Polls}

Our results also demonstrate that polls do not necessarily help subjects to improve their decisions. Specifically, when we compare subjects in the control group to subjects who receive the polls in each treatment group, we do not observe any significant differences in the amounts of money that subjects earn. Indeed, Tables 3 and 4 show that subjects who receive the polls in each treatment group do no better than subjects in the control group, who make their decisions on their own. This finding stems, in part, from the fact that treatment group subjects who receive the polls do not appear to distinguish between correct and incorrect poll results, nor do they take into account the size of the majority recommending one answer over the other. That is, the direction of the majority (regardless of whether it is correct or incorrect) exerts an enormous influence on subjects' decisions, while the size of the majority does not.

[Tables 3 and 4 about here]

The results in Table 4 illustrate the power that the direction (but not the size) of the majority has on subjects' decisions. Specifically, we find that when a majority of the pollees recommended the correct answer, subjects who receive polls earn significantly more money than subjects in the control group. However, when a majority of the pollees recommended the incorrect answer, subjects who receive polls earn significantly less money than subjects in the control group. Indeed, when the direction of the majority changes from recommending the correct answer to recommending the incorrect answer, subjects who receive the polls lose an estimated 43 cents per problem. Interestingly, Table 4 also demonstrates that the size of the 
majority recommending one answer over the other does not influence subjects' decisions. That is, moving from the smallest majority margin (where 6 pollees recommended one answer and 5 recommended the other answer, yielding a margin of 1) to the largest majority margin (where 59 pollees recommended one answer and 3 recommended the other answer, yielding a margin of 56) does not produce a significant difference in the amounts of money that subjects earn. This result holds regardless of whether the majority recommends the correct or incorrect answer ${ }^{24}$ and even when controlling for the difficulty of the problems. Thus, even though the size of the majority may not be very large and even though a bare majority may recommend the incorrect answer, the direction of the majority exerts a significant influence on subjects' decisions.

Because subjects' decisions to receive polls are not random (the results in Tables 1 and 2 show that they are not), we also conducted experiments in which all subjects were automatically given free and credible polls (as opposed to having to request them). We then compared the results of these experiments with the results from our "Free Access to Credible Polls" treatment group (where subjects choose whether to receive free and credible polls). ${ }^{25}$ This comparison allows us to determine whether polls have the same effect on subjects' decisions when subjects choose to receive them versus when they are forced to receive them (see Gaines and Kuklinski 2008, 2009 for further discussion of the advantages of this technique). Our results indicate that regardless of whether subjects choose to receive these polls or whether they are automatically given the polls, the effects that these polls have on their decisions are the same. That is, in both experiments, the direction of the majority exerts a large influence on subjects' decisions, while the size of the majority does not. Thus, even when subjects are automatically given polls, they earn significantly less money when a majority of pollees recommends the incorrect decision, regardless of the size of that majority. (See the web appendix for these results.) 


\section{Conclusion}

The results of our experiments demonstrate that when it comes to polls, "the blind lead the blind." That is, subjects are more likely to obtain polls when the decisions that they must make are difficult and when they are unsophisticated. Although this result makes a great deal of sense (i.e., we expect subjects to seek information when they are not sure of what choice to make), it is problematic because on the difficult decisions, the pollees are also uninformed and do not provide much useful information. Thus, we observe the blind pollees leading the blind subjects. Further, subjects do not appear to distinguish between credible versus non-credible polls.

Our results also show that polls do not necessarily help subjects to improve their decisions. Specifically, we find that although subjects base their decisions upon the recommendations of the majority, they do not distinguish between correct and incorrect poll results, nor do they take into account the size of the majority recommending one answer over the other. That is, the direction of the majority (regardless of whether it is correct) exerts an enormous influence on subjects' decisions, while the size of the majority does not. What this means for subjects' decisions is that when a majority of pollees recommends the correct answer, subjects who receive the polls make significantly better decisions than subjects in the control group, who make their decisions on their own. However, when a majority of pollees recommends the incorrect answer, subjects who receive polls make significantly worse decisions than subjects in the control group. These effects occur regardless of the size of the majority recommending one answer over the other. Thus, the majority's opinions about the correct choices can cause subjects to make incorrect decisions, even when the majority is not very large. 
The consequence of these findings is that subjects who receive the polls in each treatment group make decisions that are no better than the decisions of control group subjects.

Because polls are increasingly conducted by politicians and reported in the media (and because poll results are not always correct), our results contribute to the literature on polls, in particular, and to the literature on cue-taking, in general. Although many scholars suggest that cues improve citizens' decisions, our results reveal that the effectiveness of this particular cue depends upon the nature of the poll results. That is, although polls are clearly a powerful cue for citizens, ${ }^{26}$ they only help citizens to improve their decisions when a majority of pollees is in favor of the correct choice. And, because our results suggest that citizens are more likely to obtain polls when the poll results are least likely to help them (i.e., when the decisions are difficult and when they are unsophisticated), it cannot be said that polls necessarily provide citizens with cues that help them with their decisions. Indeed, what this result suggests for real world politics is that when unsophisticated citizens receive polls about what their fellow citizens think about complex, difficult issues (such as how to properly dispose of nuclear waste or what the consequences of social security privatization would be), they are unlikely to benefit from such poll results. Rather, their fellow citizens are likely to be just as uninformed about these issues as they are, which may lead citizens to make worse decisions than they would have made on their own. However, when citizens receive polls about what their fellow citizens think about simpler issues, they are more likely to receive poll results that help them with their decisions. The irony is that when the issues are simple, citizens are unlikely to need polls in the first place.

Viewed in light of the media's (over)emphasis on the precision of polls, as well as the problems associated with telephone and Internet polls, our results suggest that we have good reason to fear that "the blind lead the blind" in real world politics. Consistent with our 
experimental results, survey-based and historical research demonstrates that citizens in real world political settings put a tremendous amount of stock in what "the majority" thinks, feels, and intends to do (Herbst 1993; Igo 2007). The stock that ordinary citizens put in polls is disconcerting because scholars have shown that real world polls can be inaccurate and biased (see, e.g., Franklin 2003; Jackman 2005; Lau 1994). Thus, citizens in real world politics (like subjects in our experiments) may receive poll results that are inaccurate, yet may be swayed by these seemingly precise and scientific results.

From a methodological standpoint, our results suggest that scholars should continue to use both experimental and survey-based methods to investigate the effects that polls have on citizens' decisions. In this study, we took advantage of the strong internal validity associated with laboratory experiments and analyzed 1) the conditions under which citizens are willing to obtain polls and 2) whether and when polls help citizens to improve their decisions. However, because we examined the effects of one particular type of poll (i.e., polls about objectively correct or incorrect information), our results may overestimate the extent to which citizens in the real world base their decisions upon the recommendations of the majority. Indeed, Griskevicius et al. (2006) demonstrate that when an issue has an objectively correct answer, people are more likely to follow the majority out of fear of being proven wrong. Although many political polls contain information that is objectively correct or incorrect (i.e., whether Saddam Hussein was personally involved in the September 11 terrorist attacks), other political polls contain more subjective questions (i.e., whether respondents support or oppose the war in Iraq). Thus, scholars should be cautious when generalizing our results to more subjective polling contexts. That said, given the many polls that do tap pollees' beliefs about objective, factual information, our experiments tell us a great deal about how citizens in the real world use this type of poll. 
Further, because we focused on one particular cue, our study leaves open the question of which cues are most effective for different citizens in different contexts. Specifically, citizens in the real world may use not only poll results, but also other cues (such as endorsements and party labels) when making political decisions. Additionally, citizens' decisions to use particular cues (as well as the number of cues they use) may depend on whether they are more or less sophisticated and whether the decisions they must make are difficult versus easy. Thus, we emphasize that future research should examine whether citizens use more than one cue when making decisions, as well as which cues they choose to use in different contexts. 
${ }^{1}$ Igo (2007) describes how the media has historically presented poll results in a way that makes them seem more precise than they really are. She emphasizes that the media often summarizes complicated poll results in simplistic charts or short broadcasts that gloss over nuances and variability in the polling data. She also describes the media's tendency to present poll results in a way that makes it appear as though the public speaks in one voice, when in reality they do not (p. 143). Igo then details pollsters' efforts to persuade members of the media to present a more realistic account of how the public feels about particular issues. Herbst (1993) also notes that the media often provides an uncritical reporting of poll results and does not always properly communicate complex findings.

${ }^{2}$ Subjects are given 60 seconds to make a decision about each math problem because we found that subjects tend not to use longer amounts of time. Specifically, when pretesting these math problems for other experiments, we allowed subjects to have a longer amount of time (i.e., 90 seconds) to answer each problem. In these pretests, we discovered that subjects tend not to use this extra time, but rather sit there for the last 30 seconds, appearing quite bored and restless. Further, giving subjects 90 seconds to answer each math problem would make our experiments last even longer, which we knew from experience would tax subjects' attention spans.

${ }^{3}$ Lau and Redlawsk (1997) develop measures that assess the correctness of citizens' votes. ${ }^{4}$ Allowing the pollees to leave problems blank most likely prompts subjects to confer greater expertise on the majority. This is especially true if subjects believe that the pollees who do not know the correct answers are the ones who leave the problems blank.

${ }^{5}$ Importantly, we tell subjects in our treatment groups that these undergraduates had 60 seconds to make a decision about each math problem. 
${ }^{6}$ The math problems that subjects solve were chosen based upon the poll results that we obtained for each problem. That is, we included some math problems where a majority of pollees recommended the correct answer, some where a majority of pollees recommended the incorrect answer, and some where the poll results were closer to a 50-50 split. We also included problems that varied in how large the majority recommending the correct or incorrect answer was.

${ }^{7}$ In each session of each treatment group, there are between 12 and 14 subjects in the laboratory. To ensure that subjects' decisions to receive polls are not driven by stigmas or social desirability effects, we use several procedures. Specifically, all subjects sit behind large partitions so that they cannot see whether other subjects choose to receive the poll results on particular math problems. Additionally, subjects indicate whether they want to receive the poll results by checking "yes" or "no" on their handouts. Then, we collect all subjects' handouts to determine whether any subjects want to receive the poll results. If a subject chooses to receive the poll results, then we write the poll results for that problem on that subject's handout. Otherwise, we leave subjects' handouts blank. Regardless of how many subjects choose to receive the poll results, we take approximately one minute to write the poll results on subjects' handouts. We do this so that subjects cannot infer anything about how many other subjects chose to receive the poll results from the amount of time that it takes us to write the poll results on subjects' handouts. After we write down the poll results, we return the handouts to all of the subjects; that is, subjects either receive a blank handout or a handout containing the poll results, depending on what they chose. We do this so that subjects cannot infer which subjects (or how many subjects) chose to receive the poll results. Given the anonymity of subjects' decisions, we are confident that stigmas or social desirability effects do not confound our experiments and that our results would be no different if our experiment had been computerized. 
${ }^{8}$ Non-treatment group participants make one 60 -second decision about the answer to each math problem. Equating the total amount of time that these groups have to make their decisions would have required us to do one of two things. First, we could have given non-treatment group participants a longer amount of time to answer each problem (i.e., 120 seconds). However, when pretesting these problems, we found that students tend not to use longer amounts of time. Thus, we are confident that our results would be the same if we had equated the groups by giving nontreatment group participants a full 120 seconds to make each decision. Second, we could have given treatment group subjects less time (after the initial 60 seconds) to make their final decision about each problem (for example, 15 seconds instead of an additional 60 seconds). To equate the groups in this way, we could have given non-treatment group participants a total of 75 seconds to make their decisions. We did not do this because we feared that giving treatment group subjects only 15 seconds to make their final decisions would have limited our ability to draw conclusions about real world polls and behavior. Indeed, research shows that people are more likely to use mental shortcuts when time is limited. Thus, we ensured that treatment group subjects had ample time to make their decisions after receiving the polls and that they did not feel rushed (or forced to rely upon the polls) when making their decisions. Given these considerations, we purposely did not equate the groups with respect to the total amount of time they had to make their decisions.

${ }^{9} \mathrm{~A}$ between-group research design enables us to use the same math problems in each group. That said, in some sessions of the experiment, we had treatment group subjects answer 18 math problems, while in other sessions, we had treatment group subjects answer only ten or eleven of these problems. To account for any differences in the difficulty of the problems across groups, we control for the difficulty of the problems in our statistical analyses. 
${ }^{10}$ If the pollees had both a financial incentive to recommend correct answers and the expertise needed to recommend correct answers, we expect that subjects would rely even more heavily on the poll results. Indeed, Lupia and McCubbins (1998) demonstrate that when citizens perceive others to be both knowledgeable and trustworthy, they base their decisions upon the information that they provide. We did not use pollees who were both knowledgeable and trustworthy in our experiments because real world pollees are not always both knowledgeable and trustworthy. Further, if we had surveyed 66 math experts and paid them for recommending correct answers, we would not have had nearly as much variation in the poll results. That is, few (if any) polls would have indicated the incorrect decision or been close to a 50-50 split. Because we are interested in how variations in the size and direction of the majority affect decisions, we did not survey math experts. This is also why we did not conduct experiments in which the pollees were math experts, but did not have a financial incentive to recommend correct answers. That is, we suspected that math experts (who seem to pride themselves on knowing the correct answers) would recommend the correct answers regardless of whether they were paid for doing so.

${ }^{11}$ To guard against the possibility that subjects would simply assume that the 66 undergraduates that we polled were paid for recommending the correct answer, we use two different procedures. First, at the beginning of the experiment, we ask subjects to solve four math problems on their own. For two of these math problems, we tell subjects that they will earn money for choosing correct answers. On the other two problems, we tell subjects that they will earn money for choosing incorrect answers. By doing this, we show subjects that the 66 undergraduates that we polled did not necessarily earn money for recommending correct answers. Second, we give subjects a quiz on the instructions that we read at the beginning of the experiment, and one of the quiz questions asks subjects about how the 66 undergraduates that we polled earned money. The 
correct answer to this quiz question is "unknown," and subjects, by and large, answer this quiz question correctly. This gives us confidence that subjects are not simply assuming that the 66 undergraduates were paid for recommending correct answers.

${ }^{12}$ For a study showing that the absence of financial incentives can make citizens less likely to provide correct political information, see Prior and Lupia (2008).

${ }^{13}$ This 10-cent cost is subtracted from subjects' experimental earnings at the end of the experiment, and all subjects know this at the outset of the experiment.

${ }^{14}$ This 10 -cent cost most likely underestimates the opportunity costs that citizens face in the real world. We designed our experiments in this way because if citizens are unwilling to receive polls with only a 10 -cent cost-which is a small cost, relative to the potential benefit (50 cents) that subjects will achieve if they make a correct choice - then it is unlikely that they will do so in the real world, when they may spend time, energy, and attention that is more costly to them, relative to what they might gain. Further, given that subjects' expected payoff from guessing about the correct answer to a math problem is zero $(50 \% \mathrm{x} \$ 0.50+50 \% \mathrm{x}-\$ 0.50=0)$, subjects only need to believe that a poll will increase their probability of answering the problem correctly by $11 \%$ (i.e. from $50 \%$ to $61 \%$ ) for them to rationally pay 10 cents to receive it ( $61 \%$ x $\$ 0.50+$ $39 \% \mathrm{x}-\$ 0.50=11$ cents).

${ }^{15}$ For an overview of the social psychology literature on social influence and majority influence, see Cialdini and Goldstein (2004) and Martin, Gardikiotis, and Hewstone (2002).

${ }^{16}$ Subjects self-report their SAT math scores. Thus, we took a number of precautions to reduce (if not eliminate) subjects' incentive to inflate or misrepresent their SAT math scores.

Specifically, we made sure that subjects were not told that the experiment involved solving math problems until the experiment actually began. Also, subjects were asked to provide all of their 
SAT and SAT II scores (not just their SAT math scores) before the experiment took place. Further, it was made clear to subjects that they did not need to score above a certain number on any of the tests to participate. Subjects were also encouraged to contact the College Board, the registrar, their parents, or their high school counselors if they did not remember their scores, and they were given ample time to do this. We have evidence that many subjects contacted these people, as several subjects gave us their actual score reports, and others referenced their parents or high school counselors as having located these scores. As an ex post check on the validity of subjects' self-reported SAT math scores, we compared the distribution of our subjects' SAT math scores with the distribution of SAT math scores at the university that subjects attend. These two distributions are quite similar. That is, the university's $25^{\text {th }}-75^{\text {th }}$ percentile for SAT math scores ranges from $600-700$ points, while the $25^{\text {th }}-75^{\text {th }}$ percentile for SAT math scores in our experiments ranges from 610-710 points. Further, anecdotal evidence indicates that subjects were quite truthful when reporting their SAT scores. For example, many subjects apologized for their low test scores and lamented the fact that these scores prevented them from attending other universities. Others told us that they could not locate their test scores before the experiment and asked to be rescheduled for an experiment at a later date. Taken together, this evidence gives us much confidence that the self-reported SAT math scores are not systematically inflated or misrepresented. There may be random noise in the scores, but this should bias us against finding significant effects with respect to subjects' levels of sophistication.

${ }^{17}$ We control for these characteristics of subjects because there were small differences in them across our treatment groups.

${ }^{18}$ We use this dependent variable because it reflects the quality of each subject's decision on individual problems. We do not use a binary dependent variable that is coded " 1 " if a subject 
makes a correct decision on each problem and " 0 " if a subject makes an incorrect decision because it does not take into account the fact that subjects can (and do) leave problems blank. Similarly, a binary dependent variable that is coded "1" if a subject makes a correct decision on each problem and "0" if a subject makes an incorrect decision or leaves the problem blank treats blank and incorrect answers equally. There is an important distinction between leaving problems blank and answering problems incorrectly, and our money earned dependent variable nicely captures this distinction.

That said, we did create a trichotomous dependent variable that treats correct, incorrect, and blank answers as separate categories. Specifically, we created a dependent variable that is coded "1" if a subject answers a problem incorrectly, "2" if a subject leaves a problem blank, and "3" if a subject answers a problem correctly. We then estimated an ordered logit regression using this dependent variable instead of our money earned dependent variable. The substantive results of this regression are the same as those from the money earned regression (see p. 2 of the web appendix). From a substantive standpoint, we report the money earned results in the text because we are interested in the effects that receiving polls has on subjects' welfare, which money earned nicely captures.

${ }^{19}$ Of the 3,191 choices included in our money earned regressions, subjects earn 50 cents 1,760 times, lose 50 cents 551 times, and earn nothing 880 times.

${ }^{20}$ The number of observations listed in Table 1 reflects 170 subjects making decisions about whether to receive polls on 10 to 18 different math problems each, for a total of 2327 choices. The number of observations listed in Table 3 reflects 218 subjects making decisions about the answers to 10 to 18 different math problems each, for a total of 3191 choices. There are fewer observations in Table 1 because control group subjects are not included in that regression. There 
are 218 subjects in the model in Table 3 because some control group subjects did not provide demographic data, such as their year in school or gender. Our results do not change when these demographic variables are dropped and all control group subjects are included.

${ }^{21}$ We estimate a random effects GLS model (as opposed to a random effects OLS model) because when individual effects are uncorrelated with the other regressors (as is the case in our data), OLS is inefficient compared to GLS. As Greene (2003, p. 301) states, "under the hypothesis of no correlation [between individual effects and the other regressors], both OLS... and GLS are consistent, but OLS is inefficient."

${ }^{22}$ Using Treatment 4 as the omitted category does not affect the size or significance of the effects that Difficulty and Sophistication have on the probability that subjects choose to receive polls.

${ }^{23}$ Subjects in the "Costly Access to Credible Polls" treatment group are not less likely to follow the poll results once they choose to receive them. Indeed, regardless of whether subjects pay a cost to receive credible or non-credible polls, there is little difference in the rate at which they answer the problem correctly, incorrectly, or leave it blank.

${ }^{24}$ One might expect the size of the majority to matter less when the problems are more difficult. Specifically, it is plausible that when the problems are more difficult (and when subjects are more uncertain about the correct answer), subjects may be more likely to use the mental shortcut, "go with the majority." However, we find that the size of the majority has roughly the same effect on difficult and easy problems.

${ }^{25}$ In an ideal world, we would have been able to include several different treatment groups in which subjects are forced to view polls. For example, in an ideal world, we could force subjects to pay a cost to receive polls that are either credible or not and force them to receive free polls 
that are either credible or not. This would allow us to have 4 different treatment groups where subjects are forced to receive polls that correspond to each of our 4 different selection treatment groups. Unfortunately, our Institutional Review Boards (IRBs) would not allow us to force subjects to pay to receive polls (whether they are credible or not) because it is unethical to force subjects to give up money in an experiment. Because we cannot force subjects to pay to receive polls (and because we observed no differences between free, credible polls and free, non-credible polls), we include one treatment group where subjects are forced to receive polls that are free and credible. We find no differences in the effects of MajorityIncorrect and MajorityMargin on subjects that are forced to receive free, credible polls and subjects that choose to receive free, credible polls. These results give us great confidence that our results are not biased by selection effects, and as Gaines and Kuklinski $(2008,2009)$ note, this is the appropriate empirical strategy for comparing treatment effects with selection effects.

${ }^{26}$ Our research is related to, yet different from, Surowiecki (2004). In contrast to Surowiecki, we focus on contexts in which the majority is wrong, which leads citizens to make worse decisions than they would have made on their own. Of course, Surowiecki also considers instances in which the majority is wrong, and he suggests that groups arrive at bad judgments when there is not enough variance in thought process and private information among group members. Such homogeneity among group members may explain why the majority of pollees in our experiments did not always recommend the correct answer. Surowiecki also emphasizes that the sharing of information among group members is crucial for good decision making. However, in our experiments, the pollees were not permitted to access or share information prior to recommending an answer. 


\section{References}

Ansolabehere, Stephen and Shanto Iyengar. 1994. "Of Horseshoes and Horse Races:

Experimental Studies of the Impact of Poll Results on Electoral Behavior.” Political Communication, 11: 413-430.

Aronson, Eliot, Timothy D. Wilson, and Marilynn B. Brewer. 1998. "Experimentation in Social Psychology.” In Daniel T. Gilbert, Susan T. Fiske, and Gardner Lindzey (Eds.), The Handbook of Social Psychology, $4^{\text {th }}$ edition. New York: Oxford University Press.

Bartels, Larry M. 1988. Presidential Primaries and the Dynamics of Public Choice. Princeton: Princeton University Press.

Berelson, Bernard, Paul F. Lazarsfeld, and William N. McPhee. 1954. Voting: A Study of Opinion Formation in a Presidential Campaign. Chicago: University of Chicago Press.

Campbell, Angus, Philip Converse, Donald Stokes, and Warren Miller. 1960. The American Voter. New York: John Wiley.

Ceci, Stephen J. and Edward L. Kain. 1982. "Jumping on the Bandwagon With the Underdog: Impact of Attitude Polls on Polling Behavior.” Public Opinion Quarterly, 46: 228-242.

Cialdini, Robert B. and Noah J. Goldstein. 2004. "Social Influence: Compliance and Conformity." Annual Review of Psychology, 55: 591-621.

Converse, Philip E. 1964. "The Nature of Belief Systems in Mass Publics." In D.E. Apter, ed., Ideology and Discontent. New York: Free Press.

Delli Carpini, Michael X. and Scott Keeter. 1996. What Americans Know About Politics and Why It Matters. New Haven: Yale University Press.

Druckman, James N. 2001. "The Implications of Framing Effects for Citizen Competence." Political Behavior, 23(3): 225-256. 
Fowler, James H. and Cindy D. Kam. 2006. "Patience as a Political Virtue: Delayed Gratification and Turnout." Political Behavior, 28: 113-128.

Franklin, Charles. 2003. "Polls, Election Outcomes, and Sources of Error." Paper presented at the annual meeting of the American Association for Public Opinion Research, Sheraton Music City, Nashville, TN, August 16, 2003.

Gaines, Brian J. and James H. Kuklinski. 2009. “Treatment Effects.” In James N. Druckman, Donald P. Green, James H. Kuklinski, and Arthur Lupia (eds.), Handbook of Experimental Political Science. Cambridge University Press (forthcoming).

Gaines, Brian J. and James H. Kuklinski. 2008. “A Case for Including Self-Selection alongside Randomization in the Assignment of Experimental Treatments." Paper presented at the annual meeting of the Midwest Political Science Association, Chicago, IL.

Geer, John G. 1996. From Tea Leaves to Opinion Polls: A Theory of Democratic Leadership. New York: Columbia University Press.

Greene, William H. 2003. Econometric Analysis, $5^{\text {th }}$ edition. Upper Saddle River: Prentice Hall. Griskevicius, V., Noah J. Goldstein, Chad R. Mortensen, Robert B. Cialdini, and Douglas T. Kenrick. 2006. “Going Along Versus Going Alone: When Fundamental Motives Facilitate Strategic (Non)Conformity." Journal of Personality and Social Psychology, 91(2): 281-294.

Hardy, Bruce W. and Kathleen Hall Jamieson. 2005. "Can a Poll Affect Perception of Candidate Traits?" Public Opinion Quarterly, 69(5): 725-743.

Herbst, Susan. 1993. Numbered Voices: How Opinion Polling Has Shaped American Politics. Chicago: University of Chicago Press. 
Hibbing, John R. and Elizabeth Theiss-Morse. 2002. Stealth Democracy: Americans’ Beliefs about How Government Should Work. Cambridge: Cambridge University Press.

Igo, Sarah E. 2007. The Averaged American: Surveys, Citizens, and the Making of a Mass Public. Cambridge: Harvard University Press.

Irwin, Galen A. and Joop J. M. Van Holsteyn. 2002. "According to the Polls: The Influence of Opinion Polls on Expectations.” Public Opinion Quarterly, 66: 92-104.

Jackman, Simon. 2005. "Pooling the Polls Over an Election Campaign.” Australian Journal of Political Science, 40(4): 499-517.

Jacobs, Lawrence R. and Robert Y. Shapiro. 1995-1996. "Presidential Manipulation of Polls and Public Opinion: The Nixon Administration and the Pollsters.” Political Science Quarterly, 110(4): 519-538.

Kam, Cindy D. 2005. "Who Toes the Party Line? Cues, Values, and Individual Differences." Political Behavior, 27(2): 163-182.

Kam, Cindy D. and Barbara Sommer. 2006. "Real-Time Polling Technology in a Public Opinion Course.” PS: Political Science and Politics, 39(1): 113-117.

Key, V.O., Jr. 1966. The Responsible Electorate: Rationality in Presidential Voting, 1936-1960. Cambridge: Harvard University Press.

Lau, Richard R. 1994. “An Analysis of the Accuracy of 'Trial Heat' Polls During the 1992 Presidential Election.” Public Opinion Quarterly, 58: 2-20.

Lau, Richard R. and David P. Redlawsk. 1997. "Voting Correctly.” American Political Science Review, 91: 585-599.

Lavrakas, Paul J. and Michael W. Traugott (eds.). 2000. Election Polls, the News Media, and Democracy. New York: Chatham House. 
Lippman, Walter. 1925. The Phantom Public. New York: Macmillan.

Lupia, Arthur 1994. "Shortcuts versus Encyclopedias: Information and Voting Behavior in California Insurance Reform Elections." American Political Science Review, 88: 63-76.

Lupia, Arthur and Mathew D. McCubbins. 1998. The Democratic Dilemma: Can Citizens Learn What They Need to Know? Cambridge: Cambridge University Press.

Luskin, Robert C. 1987. "Measuring Political Sophistication.” American Journal of Political Science 31: 856-899.

Martin, Robin, Antonis Gardikiotis, and Miles Hewstone. 2002. "Levels of Consensus and Majority and Minority Influence." European Journal of Social Psychology, 32: 645-665. McAllister, Ian and Donley T. Studlar. 1991. "Bandwagon, Underdog, or Projection? Opinion Polls and Electoral Choice in Britain, 1979-1987." Journal of Politics, 53(3): 720-741.

Mutz, Diana C. 1992. "Impersonal Influence: Effects of Representations of Public Opinion on Political Attitudes." Political Behavior, 14(2): 89-122.

Mutz, Diana C. 1997. “Mechanisms of Momentum: Does Thinking Make It So?” Journal of Politics, 59(1): 104-125.

Polsby, Nelson and Aaron Wildavsky. 1980. Presidential Elections. New York: Scribner's. Popkin, Samuel L. 1991. The Reasoning Voter: Communication and Persuasion in Presidential Campaigns. Chicago: University of Chicago Press.

Prior, Markus and Arthur Lupia. 2008. “Money, Time, and Political Knowledge: Distinguishing Quick Recall and Political Learning Skills.” American Journal of Political Science, 52(1): 169-183.

Sniderman, Paul M., Richard A. Brody, and Philip E. Tetlock. 1991. Reasoning and Choice: Explorations in Political Psychology. New York: Cambridge University Press. 
Surowiecki, James. 2004. The Wisdom of Crowds: Why the Many are Smarter Than the Few and How Collective Wisdom Shapes Business, Economies, Societies, and Nations. New York: Random House.

Tomz, Michael, Jason Wittenberg, and Gary King. 2003. CLARIFY: Software for Interpreting and Presenting Statistical Results. Available at http://gking.harvard.edu/

West, Darrell M. 1991. “Polling Effects in Election Campaigns.” Political Behavior, 13: 151163. 
Table 1. The Effects that Sophistication, Decision Difficulty, and each Treatment have on Subjects' Decisions to Receive the Poll Results

\begin{tabular}{|c|c|c|}
\hline \multirow[t]{2}{*}{ Independent Variables } & \multicolumn{2}{|c|}{$\begin{array}{c}\text { Dependent Variable = } \\
\text { Whether Each Subject Chooses to Receive Poll } \\
\text { Results on Each Problem }\end{array}$} \\
\hline & Random Effects Logit & Logit \\
\hline $\begin{array}{c}\text { Treatment } 1 \\
\text { (free, credible polls) }\end{array}$ & $\begin{array}{l}4.282^{*} \\
(0.401)\end{array}$ & $\begin{array}{l}3.015^{*} \\
(0.159)\end{array}$ \\
\hline $\begin{array}{c}\text { Treatment } 2 \\
\text { (free, non-credible polls) }\end{array}$ & $\begin{array}{l}5.238^{*} \\
(0.595)\end{array}$ & $\begin{array}{l}3.313^{*} \\
(0.191)\end{array}$ \\
\hline $\begin{array}{c}\text { Treatment } 3 \\
\text { (costly, credible polls) }\end{array}$ & $\begin{array}{c}0.390 \\
(0.377)\end{array}$ & $\begin{array}{c}0.251 \\
(0.165)\end{array}$ \\
\hline Sophistication & $\begin{array}{l}-0.005^{*} \\
(0.002)\end{array}$ & $\begin{array}{l}-0.004^{*} \\
(0.001)\end{array}$ \\
\hline Difficulty & $\begin{array}{l}0.023^{*} \\
(0.002)\end{array}$ & $\begin{array}{l}0.016^{*} \\
(0.002)\end{array}$ \\
\hline Year in school & $\begin{array}{l}0.271 * \\
(0.122)\end{array}$ & $\begin{array}{l}0.131^{*} \\
(0.055)\end{array}$ \\
\hline Female & $\begin{array}{c}0.288 \\
(0.392)\end{array}$ & $\begin{array}{l}-0.068 \\
(0.119)\end{array}$ \\
\hline Constant & $\begin{array}{c}1.632 \\
(1.331)\end{array}$ & $\begin{array}{l}1.705^{*} \\
(0.527)\end{array}$ \\
\hline $\begin{array}{c}\text { rho } \\
\text { Log likelihood } \\
\mathrm{N}= \\
\text { Groups (i.e., subjects) }=\end{array}$ & $\begin{array}{c}0.562 \\
-876.08 \\
2327 \\
170 \\
\end{array}$ & $\begin{array}{c}-- \\
-1108.73 \\
2327 \\
--\end{array}$ \\
\hline
\end{tabular}

Omitted category $=$ Treatment 4 (costly, non-credible polls)

Standard errors in parentheses; ${ }^{*} p<0.05$ 
Table 2. The Effects that Sophistication, Decision Difficulty and each Treatment have on the Likelihood that Subjects Choose to Receive Polls

\begin{tabular}{|c|c|c|}
\hline When this variable... & Shifts from ... to ... & $\begin{array}{c}\text { Change in } \\
\text { Probability of } \\
\text { Receiving Poll } \\
\text { (confidence interval) } \\
\end{array}$ \\
\hline Treatment 1 & $\begin{array}{l}0 \text { to } 1 \\
\text { (i.e., from "Costly Access to } \\
\text { Non-Credible Polls" to "Free } \\
\text { Access to Credible Polls") }\end{array}$ & $\begin{array}{c}0.64 \\
(0.587,0.680)\end{array}$ \\
\hline Treatment 2 & $\begin{array}{l}0 \text { to } 1 \\
\text { (i.e., from "Costly Access to } \\
\text { Non-Credible Polls" to "Free } \\
\text { Access to Non-Credible Polls") }\end{array}$ & $\begin{array}{c}0.68 \\
(0.627,0.726)\end{array}$ \\
\hline Treatment 3 & $\begin{array}{l}0 \text { to } 1 \\
\text { (i.e., from "Costly Access to } \\
\text { Non-Credible Polls" to "Costly } \\
\text { Access to Credible Polls") }\end{array}$ & $\begin{array}{c}0.04 \\
(-0.012,0.087)\end{array}$ \\
\hline Difficulty & Easiest to Hardest & $\begin{array}{c}0.16 \\
(0.122,0.208)\end{array}$ \\
\hline Sophistication & 800 to 400 & $\begin{array}{c}0.29 \\
(0.192,0.404)\end{array}$ \\
\hline
\end{tabular}

Effects indicate first differences with all treatment variables set to zero and all other variables held constant at their median values. Boldface indicates that the $95 \%$ confidence interval around a simulated first difference did not contain zero, signifying statistical significance. Based on the Logit model presented in Table 1, with first differences drawn from 1000 simulations performed by CLARIFY (Tomz, Wittenberg, and King 2003). 
Table 3. Determinants of the Amount of Money Subjects Earn*

\begin{tabular}{|c|c|c|}
\hline \multirow[t]{2}{*}{ Independent Variables } & \multicolumn{2}{|c|}{$\begin{array}{l}\text { Dependent Variable }=\text { Amount of Money that } \\
\text { Each Subject Earns on Each Problem }\end{array}$} \\
\hline & Random Effects GLS & OLS Model \\
\hline $\begin{array}{l}\text { Treatment } 1 \\
\text { (free, credible polls) }\end{array}$ & $\begin{array}{l}0.104^{*} \\
(0.032)\end{array}$ & $\begin{array}{l}0.108^{*} \\
(0.027)\end{array}$ \\
\hline $\begin{array}{l}\text { Treatment } 2 \\
\text { (free, non-credible polls) }\end{array}$ & $\begin{array}{l}0.098^{*} \\
(0.037)\end{array}$ & $\begin{array}{l}0.104^{*} \\
(0.033)\end{array}$ \\
\hline $\begin{array}{l}\text { Treatment } 3 \\
\text { (costly, credible polls) }\end{array}$ & $\begin{array}{l}0.071^{*} \\
(0.024)\end{array}$ & $\begin{array}{l}0.074^{*} \\
(0.019)\end{array}$ \\
\hline $\begin{array}{l}\text { Treatment } 4 \\
\text { (costly, non-credible polls) }\end{array}$ & $\begin{array}{l}0.072^{*} \\
(0.024)\end{array}$ & $\begin{array}{l}0.072^{*} \\
(0.020)\end{array}$ \\
\hline Sophistication & $\begin{array}{l}0.001^{*} \\
(0.000)\end{array}$ & $\begin{array}{l}0.001^{*} \\
(0.000)\end{array}$ \\
\hline Difficulty & $\begin{array}{l}-0.006^{*} \\
(0.000)\end{array}$ & $\begin{array}{l}-0.006^{*} \\
(0.000)\end{array}$ \\
\hline Receive Poll $\mathrm{x}$ Treatment 1 & $\begin{array}{c}0.036 \\
(0.111)\end{array}$ & $\begin{array}{c}0.053 \\
(0.098) \\
\end{array}$ \\
\hline Receive Poll x Treatment 2 & $\begin{array}{c}0.024 \\
(0.132)\end{array}$ & $\begin{array}{c}0.038 \\
(0.102) \\
\end{array}$ \\
\hline Receive Poll x Treatment 3 & $\begin{array}{c}0.048 \\
(0.103)\end{array}$ & $\begin{array}{c}0.067 \\
(0.090) \\
\end{array}$ \\
\hline Receive Poll $\mathrm{x}$ Treatment 4 & $\begin{array}{c}0.064 \\
(0.111)\end{array}$ & $\begin{array}{c}0.086 \\
(0.098)\end{array}$ \\
\hline Receive Poll x Sophistication & $\begin{array}{l}-0.000^{*} \\
(0.000)\end{array}$ & $\begin{array}{l}-0.001^{*} \\
(0.000)\end{array}$ \\
\hline Receive Poll x Difficulty & $\begin{array}{c}0.000 \\
(0.001)\end{array}$ & $\begin{array}{c}0.000 \\
(0.001)\end{array}$ \\
\hline Receive Poll x Majority Margin & $\begin{array}{c}-0.001 \\
(0.001)\end{array}$ & $\begin{array}{l}-0.001 \\
(0.001)\end{array}$ \\
\hline Receive Poll x Majority Incorrect & $\begin{array}{l}-0.431^{*} \\
(0.028)\end{array}$ & $\begin{array}{l}-0.432 * \\
(0.028) \\
\end{array}$ \\
\hline Year in school & $\begin{array}{c}-0.006 \\
(0.007)\end{array}$ & $\begin{array}{c}-0.006 \\
(0.005)\end{array}$ \\
\hline Female & $\begin{array}{c}-0.016 \\
(0.014)\end{array}$ & $\begin{array}{c}-0.016 \\
(0.011)\end{array}$ \\
\hline Constant & $\begin{array}{c}-0.084 \\
(0.087) \\
\end{array}$ & $\begin{array}{c}-0.106 \\
(0.072) \\
\end{array}$ \\
\hline $\begin{array}{c}\text { rho } \\
\mathrm{R}^{2} \\
\mathrm{~N}= \\
\text { Groups (i.e., subjects)= }\end{array}$ & $\begin{array}{c}0.043 \\
0.423 \\
3191 \\
218 \\
\end{array}$ & $\begin{array}{c}- \\
0.423 \\
3191 \\
-- \\
\end{array}$ \\
\hline
\end{tabular}

Omitted category $=$ Control group; Standard errors in parentheses; ${ }^{*} p<0.05$

*We did not include a main effect for Receive Poll because subjects can only receive polls if they are in one of the treatment groups. Note also that we estimated these models with a threeway interaction between Receive Poll, Majority Margin, and Majority Incorrect. The results reported in this table and in the text do not change when this additional interaction is included. 
Table 4. How the Treatments and Poll Characteristics Change the Amount of Money

Earned

\begin{tabular}{|c|c|}
\hline When subjects shift from...to..., all else constant & $\begin{array}{c}\begin{array}{c}\text { Change in Money Earned } \\
\text { (confidence interval) }\end{array} \\
\end{array}$ \\
\hline $\begin{array}{l}\text { Control group to Receiving Polls in Treatment } 1 \\
\text { (i.e., "Free Access to Credible Polls") }\end{array}$ & $\begin{array}{c}\$ 0.16 \\
(-0.009,0.348)\end{array}$ \\
\hline $\begin{array}{l}\text { Control group to Receiving Polls in Treatment } 2 \\
\text { (i.e., "Free Access to Non-Credible Polls") }\end{array}$ & $\begin{array}{c}\$ 0.15 \\
(-0.033,0.330)\end{array}$ \\
\hline $\begin{array}{l}\text { Control group to Receiving Polls in Treatment } 3 \\
\text { (i.e., "Costly Access to Credible Polls") }\end{array}$ & $\begin{array}{c}\$ 0.14 \\
(-0.022,0.328)\end{array}$ \\
\hline $\begin{array}{l}\text { Control group to Receiving Polls in Treatment } 4 \\
\text { (i.e., "Costly Access to Non-Credible Polls") }\end{array}$ & $\begin{array}{c}\$ 0.16 \\
(-0.020,0.354)\end{array}$ \\
\hline $\begin{array}{c}\text { Receiving Poll with a Margin of } 1 \text { to Receiving Poll } \\
\text { with a Margin of 56* }\end{array}$ & $\begin{array}{c}-\$ 0.06 \\
(-0.168,0.036)\end{array}$ \\
\hline Receiving Correct Poll to Receiving Incorrect Poll & $\begin{array}{c}-\$ 0.43 \\
(-0.489,-0.374)\end{array}$ \\
\hline
\end{tabular}

Effects indicate first differences with all treatment variables set to zero and all other variables held constant at their median values. Boldface indicates that the $95 \%$ confidence interval around a simulated first difference did not contain zero, signifying statistical significance. Based on the OLS model reported in Table 3, with first differences drawn from 1000 simulations performed by CLARIFY (Tomz, Wittenberg, and King 2003).

*Note that when the majority margin shifts from 1 to 56 , the variable Receive Poll $x$ Majority Incorrect is set to zero (i.e., the poll is correct). We also find an insignificant effect of majority margin when Receive Poll $x$ Majority Incorrect is set to one (i.e., the poll is incorrect). 